\title{
Mechanical properties of dystrophic mouse muscle
}

\author{
J. B. HARRIS ${ }^{1}$ AND P. WILSON ${ }^{2}$ \\ From the Muscular Dystrophy Group Research Laboratories, Newcastle upon Tyne General Hospital, \\ Newcastle upon Tyne
}

SUMMARY A physiological method of estimating the number of motor units in normal and dystrophic muscles has revealed a large reduction in the number of motor units in dystrophic muscles. Anatomical confirmation of the results has been obtained. Dystrophic muscles also exhibit a 'myasthenic-like' response to high frequency stimulation. It is suggested that the nerve fibre is primarily affected in murine dystrophy.

Although murine dystrophy was first reported many years ago (Michelson, Russell, and Harman, 1955), the mechanical properties of dystrophic muscle have received little attention. Moreover, the available information has, without exception, been obtained on isolated muscles maintained at temperatures of 15-20 $\mathrm{C}$ (Sandow and Brust, 1958; Brust, 1965, 1966; Hinterbüchner, Angyan, and Hirsch, 1966). For three reasons, the validity of the results so obtained may be questioned. Isolated mammalian skeletal muscle rapidly becomes hypoxic, gains sodium ions and loses potassium ions (Krnjević and Miledi, 1958; Creese, 1960; Creese and Northover, 1961) low temperatures have a marked effect on the mechanical properties of mammalian skeletal muscles, and may lead to misleading figures of, for example, twitch/tetanus ratio (Buller, Ranatunga, and Smith, 1968; Close and Hoh, 1968); direct stimulation of isolated, curarized muscle bears little relationship to the disease process, especially since it is now known that neuromuscular transmission may be impaired (McComas and Mrożek, 1967).

This paper describes some mechanical properties of the tibialis anterior muscle of normal and dystrophic mice measured by an in vivo technique.

\section{MATERIALS AND METHODS}

PREPARATION OF ANIMALS Homozygous normal or dystrophic mice of the Bar Harbor 129 strain of either sex aged 90-140 days were used in this study. The animals were anaesthetized with urethane $(25 \mathrm{mg} / \mathrm{kg}$ I.P.) and a tracheostomy was performed. The tibialis anterior muscle was carefully separated from the sur-

'Present address: Department of Pharmacology Sölvegatan 10, S-223 62 LUND/Sweden.

2Present address: Department of Physiology and Biophysics, University of Washington School of Medicine, St. Louis, Missouri, U.S.A. rounding tissues, particular attention being paid to the preservation of the blood supply. The sciatic nerve was exposed in the thigh, and all muscles, other than tibialis anterior, were denervated. The tendon of insertion of the muscle was tied into a wire loop, keeping the length of free tendon as short as possible so as to reduce the compliance of the recording system, and the free ens of the wire was soldered to the strain gauge. The wire used was silver, $0 \cdot 1 \mathrm{~mm}$ diameter. The compliance of the recording system was $0.41 \mathrm{~mm} / \mathrm{kg}$. We do not know the compliance of the muscle resulting from intramusculat tendon, tendon of origin and the internal series elasticity of the fibres.

The animals were mounted in a bath of light liquio paraffin maintained at $37 \pm 1^{\circ} \mathrm{C}$ by heating coils. The tibia was firmly clamped just distal to the tibial crest with? a pair of adjustable forceps. The distal stump of the nerve was mounted on a pair of silver wire electrodes.

MECHANICAL RECORDING Isometric tension was measured using an RCA 5734 strain gauge in a specially designed holder. Loaded, the strain gauge had a natural frequency of $800 \mathrm{cycles} / \mathrm{sec}$ and was linear over the range 0-500 $\mathrm{g}$; it was calibrated before each experiment. The output of the strain gauge bridge was fed into a d.c. amplifier, and then displayed on either a Tektronix 564 storage oscilloscope, or a Tektronix 565 oscilloscope. The output of the bridge was also differentiated to provide information on the maximum rate of rise of tension. Differentiation was achieved by using a unity gain source follower feeding a differential amplifier connected operationally as a differentiator.

ELECTRICAL RECORDING Muscle action potentials were recorded extracellularly using a form of tendon-tendon recording. The wire connecting the muscle to the strain gauge formed one electrode. The other electrode was a stainless steel spring clip which was pinned into the foot. The EMG was fed into a Tektronix FM122 amplifier and then into the oscilloscope.

Time marks were obtained from a Devices Digitimer, which also served as the master stimulator. 
EXPERIMENTAL PROCEDURE The setting up completed, the strain gauge was aligned to the natural pull of the muscle, and the resting tension on the muscle adjusted until the twitch response was maximal. Evidence for a back response was next sought (Brown and Matthews, 1960; Buller and Lewis, 1965); no evidence of such an event was ever found. A tetanus was then given (300 shocks/sec for $100-200 \mathrm{msec}$ ) and the muscle allowed to rest for $15 \mathrm{~min}$. This first tetanus had the effect of completely straightening the wire, and it became necessary to reset the resting tension on the muscle. A series of 10 twitch responses was then obtained, and each response was stored in turn on the 564 oscilloscope for immediate analysis. The data retrieved from each response were: twitch tension $(\mathrm{Pt})$, contraction time $(\mathrm{CT})$, half-relaxation time ( $\left.\frac{1}{2} \mathrm{RT}\right)$, maximum rate of rise of tension $(\mathrm{d} P / \mathrm{d} t)$, and usually, amplitude of the EMG.CT, $\frac{1}{2} \mathrm{RT}$, and $\mathrm{d} P / \mathrm{d} t$ were all measured from the differentiated twitch response. The final values accepted for each of these parameters were the means of the 10 responses obtained. Next, the effect of tetanic stimulation was observed. For these experiments, full tetanic tension is defined as the maximum tension reached during stimulation at a frequency of 300 shocks/sec. The duration of the stimulus train was $100-200 \mathrm{msec}$. Since the maximum tension observed was always reached within $75 \mathrm{msec}$ (with the exception of rates of stimulation $<100$ shocks $/ \mathrm{sec}$ ) the duration of the train had no effect on the final tension of the muscle. Similarly, where figures for the maximum rate of rise of tension during a tetanus are quoted without qualification, a frequency of 300 shocks/sec was used.

In some experiments the relationships between maximum tension, maximum rate of rise of tension and rate of stimulation were investigated (Buller and Lewis, 1965). During these experiments, we used tetani of 50-700 shocks/sec for durations long enough to allow a plateau of tension to be reached (100-200 msec). Between each tetanus, twitch responses were obtained to 'monitor' the general condition of the muscle. As long as $P t$ and $\mathrm{d} P / \mathrm{d} t$ were constant, the experiment was continued. A reduction of more than $7.5 \%$ in either parameter was considered to reflect substantial deterioration of the preparation, and the experiment was terminated.

THE ESTIMATION OF MOTOR UNITS The method used to elicit contractions of single motor units was that of threshold stimulation of the sciatic nerve (Close, 1967). The smallest all-or-nothing response recorded was considered to be due to the excitation of the most excitable motor unit. The stimulus strength was then increased until an increment in the twitch tension was recorded. This new response was considered to be due to the recruitment of a second unit. In this way, the responses of a series of putative units could be obtained. The responses to maximal stimulation of the muscle was then measured. Thus it was possible to make two estimates of the number of units in a muscle: maximal twitch tension/twitch tension of the lowest threshold unit, and maximal twitch tension/mean twitch tension of the series of units. The latter estimate was made on the basis of the mean amplitude of the first four units only, due to the difficulty of obtaining larger number of units without the problems of 'alternation' (see Discussion). In all muscles, the first four units were readily recruited in reproducible order.

NERVE FIBRE COUNTS Tibialis anterior muscles of normal and dystrophic adult mice were dissected with the nerve supply intact. The nerve-muscle preparations were fixed in Flemming's solution without acetic acid for four hours and embedded in paraffin. $5 \mu$ sections were cut commencing at the muscle. The nerve branches supplying the muscle were recognized as they left the muscle, and were followed, in serial section, until just before they joined the main nerve trunk. Nerve fibres were counted from photographic reproduction of the sections, and diameters were measured using a perforated Perspex protractor device (Encapsil Ltd., Feltham, Middlesex).

STATISTICAL ANALYSIS OF RESUlts Mean values are quoted \pm standard error (SE). The significance of the difference between the means was estimated using the student $t$ test, unless there was a significant variance ratio, in which case Welch's test was used.

\section{RESULTS}

The results of these experiments are presented in the Table. For ease of handling, the results are described in detail under appropriate subheadings.

WEIGHT As described by many other workers (Sandow and Brust, 1958; Brust, 1966; Goldspink and Rowe, 1968) the dystrophic mice were distinctly lighter than normals. This weight loss was also reflected in the low weight of dystrophic muscles compared with normals.

CONTRACTILE FORCE Twitch and tetanic tensions were lower in the dystrophic muscles, when expressed in either absolute terms or tension/unit wet weight. The twitch/tetanus ratio was significantly reduced.

TWITCH KINETICS The contraction and half relaxation times of dystrophic muscles were both significantly longer than in normal muscles. The prolongation of half relaxation time was greater than that of contraction time $(125 \%$ and $115 \%$ normal values respectively). However, the variation of these parameters in the dystrophic muscles was considerable, and showed overlap with the normal muscles. Thus, the range of contraction time in normal muscles of $7 \cdot 0-9 \cdot 0$ msec may be compared with a range of $8 \cdot 4-12 \cdot 1 \mathrm{msec}$ in the dystrophic muscles; similarly the range of half relaxation times in normal muscles of $6 \cdot 0-8 \cdot 0 \mathrm{msec}$ may be compared with a range of $7 \cdot 4-10 \cdot 2 \mathrm{msec}$ in dystrophic muscles. The prolongation of relaxation was not due to repetitive firing (see also McComas and Mossawy, 1965). 
TABLE

MECHANICAL PROPERTIES OF NORMAL AND DYSTROPHIC TIBIALIS ANTERIOR MUSCLES. RESULTS EXPRESSED AS MEAN \pm STANDARD ERROR

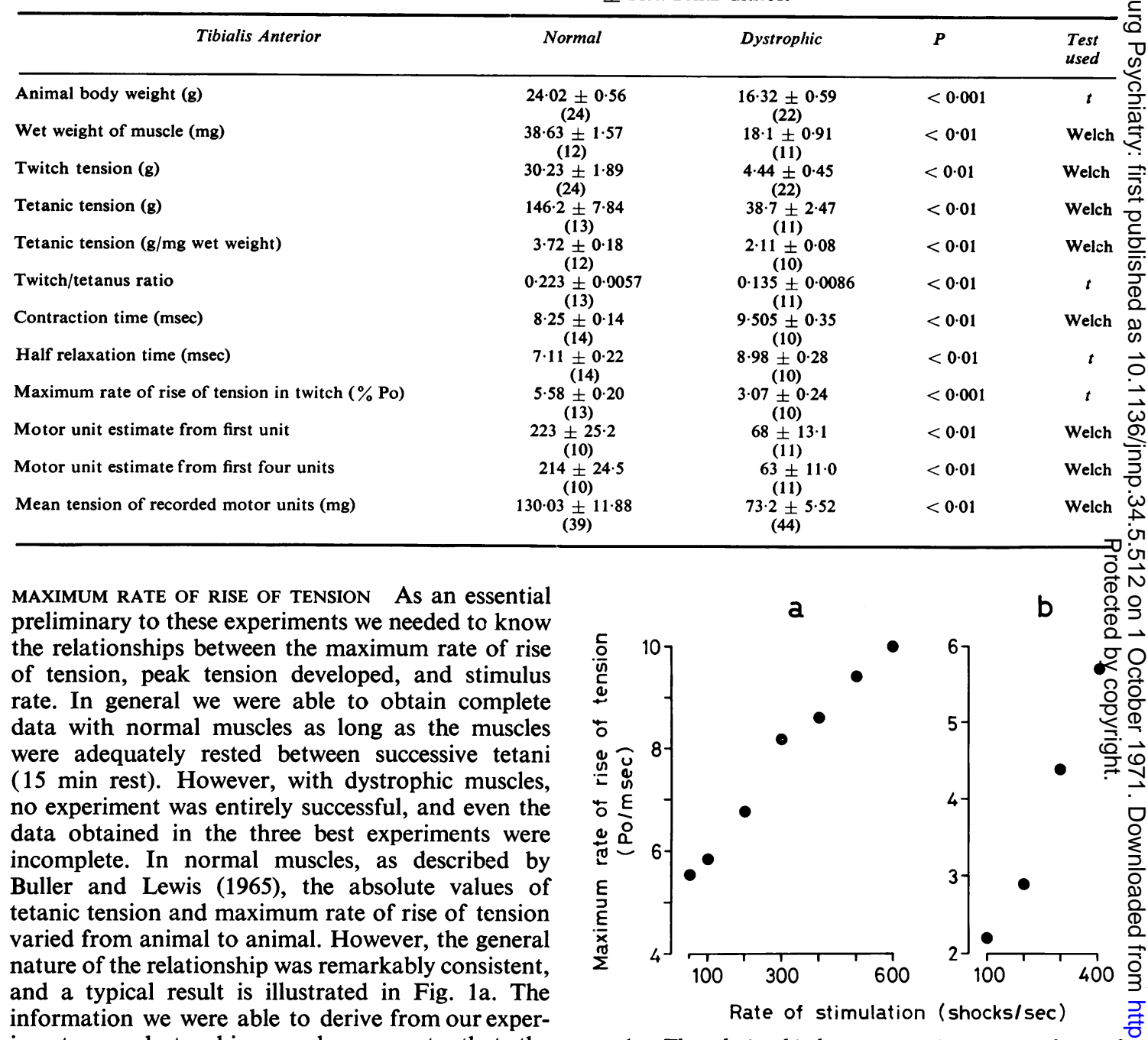
iments on dystrophic muscles suggests that the relationship between the parameters is essentially similar to that of normal muscles. We found no evidence of a change in 'fusion frequency'. A partially complete experiment is illustrated on Fig. 1b.

These results led to some difficulty in deciding the best method of comparing the properties of the two muscles. It seemed reasonable, however, to define Po as the maximum tension maintained by the muscle when stimulated at 300 shocks/sec., since in every muscle examined, tension was maximal at this rate of stimulation. Moreover, since we wished to use a derived term to compare the maximum rate of
FIG. 1. The relationship between maximum rate of rise of tension $(\% \mathrm{Po} / \mathrm{msec})$ and rate of stimulation in a, a normal muscle, and b, a dystrophic muscle. The relationship in normal muscles was always as illustrated, although the absolute figures varied from animal to animal. The result $\underline{3}$. shown for a dystrophic muscle is the most complete 8 experiment made. Note the difference in vertical scale $\frac{0}{3}$ between $\mathrm{a}$ and $\mathrm{b}$.

rise of tension in our two types of muscle $(\% \mathrm{Po} / \mathrm{N}$ $\mathrm{msec})$, it seemed reasonable to define the maximum rate of rise of tension during a tetanus as that observed at 300 shocks/sec. Obviously it would have $\underset{\omega}{\omega}$ 
been of interest to determine the true maximum rate of rise of tension in both muscles. In the normal muscles, this appeared to occur at rates of stimulation of at least 600 shocks/sec. We do not have this information for dystrophic muscles.

The maximum rate of rise of tension during both twitch and tetanus was significantly reduced in dystrophy. An analysis of the twitch contraction time and maximum rate of rise of tension during the twitch, including data from both normal and dystrophic muscles, revealed a significant correlation between the two parameters (correlation coefficient $=0.74 ; \quad$ standard error $=0.236 ; t$ test ratio $=3.14$ (Fig. 2). It would appear that the maximum rate of rise of tension during the twitch is a function only of contraction time.

NUMBERS OF MOTOR UNITS Typical experiments of the kind made to estimate the number of units in tibialis anterior muscles are shown in Fig. 3. There was a close correlation between estimates of the number of motor units based on the twitch tension of the lowest threshold unit, and the average tension generated by the first four units. Of particular interest, however, is the highly significant reduction in the number of units in dystrophic muscle. In only one out of 11 adult dystrophic mice was

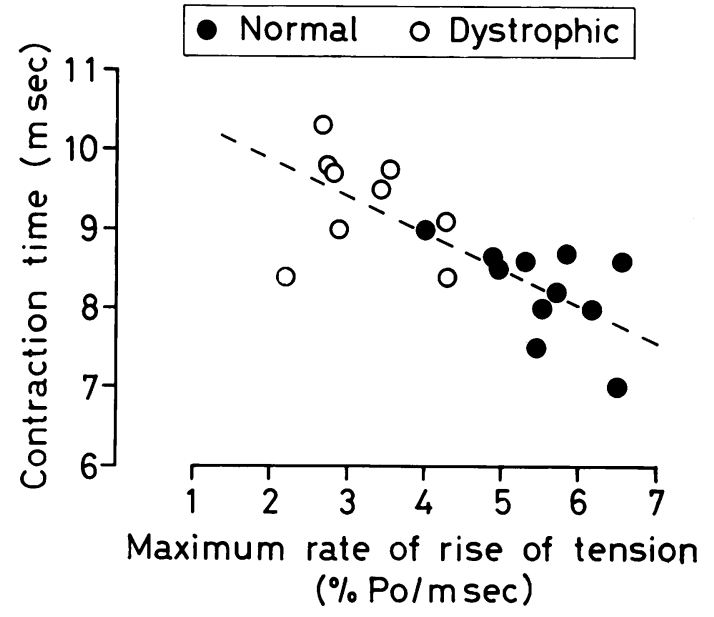

FIG. 2. The relationship between contraction time and maximum rate of rise of tension during a twitch (expressed as $\% \mathrm{Po} / \mathrm{msec}$ ). The regression line was plotted by the method of least squares, and has the characteristics $\mathrm{y}=0.459 \mathrm{x}+10.78$. The correlation coefficient was $+0 \cdot 74, S E 0 \cdot 236$.

there a normal number of motor units. The mean tension generated by single units in adult dystrophic

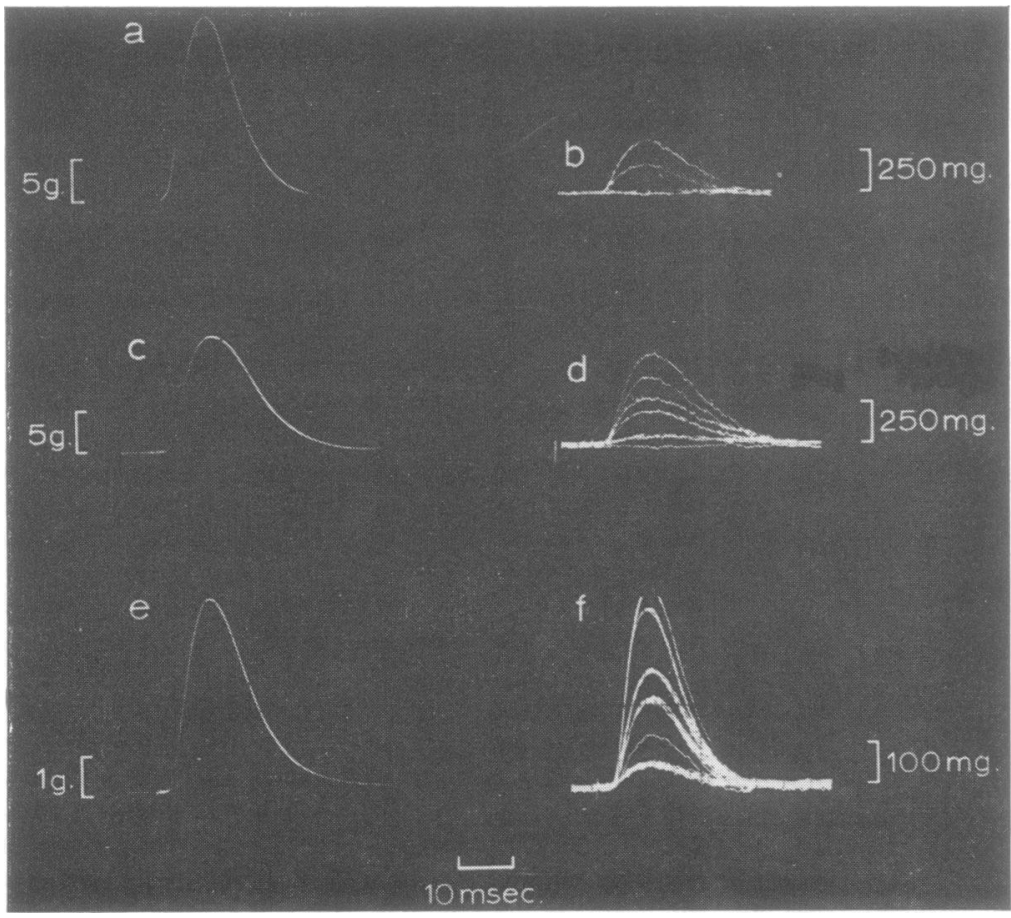

FIG. 3. Maximal twitch responses of muscles $(\mathrm{a}, \mathrm{c}, \mathrm{e})$ and responses of motor units (b, d, f) of tibialis anterior muscles. $\mathrm{a}, \mathrm{b}$, twitch and first two units of normal muscle; $\mathrm{c}, \mathrm{d}$, twitch and first five units of another normal muscle; e, $\mathrm{f}$, twitch and first five units of a dystrophic muscle. 
muscles was significantly reduced. Even so, the majority of dystrophic units were capable of generating tensions within the normal range (Fig. 4). Since the amplitude of the smallest unit measured was considerably larger than the noise level of the recording apparatus, it is inconceivable that the reduction in motor unit numbers was experimental artefact due to the 'loss' of very small units in noise. In young (4 weeks old) normal and dystrophic mice, the estimated number of motor units did not differ from estimates made on the adults. However, the remaining motor units in young dystrophics were capable of generating tensions of normal amplitude (normal unit tension: $60.57 \pm 6.57 \mathrm{mg}, n=7$; dystrophic: $64 \cdot 38 \pm 7 \cdot 11 \mathrm{mg}, n=13$ ).

ELECTRICAL ACTIVITY IN THE MUSCLE DURING REPETITIVE NERVE STIMULATION In several experiments the electrical responses of the muscles to repetitive nerve stimulation were examined (Fig. 5). Stimulation at a rate of 50 shocks/sec for $400 \mathrm{msec}$ caused a decrement between the 1st and 20th response of $2 \%$ in normal muscles, but $10 \%$ in dystrophic muscles. At 200 shocks/sec for 100 msec, the decrement was $17 \%$ in normal muscles, and $60 \%$ in dystrophic muscles.

\section{DISCUSSION}

The numbers of motor units in the tibialis anterior muscles have been estimated approximately by dividing the maximal muscle twitch tension by (a) the twitch tension of the most excitable motor unit, and (b) by the mean twitch tension of the first four

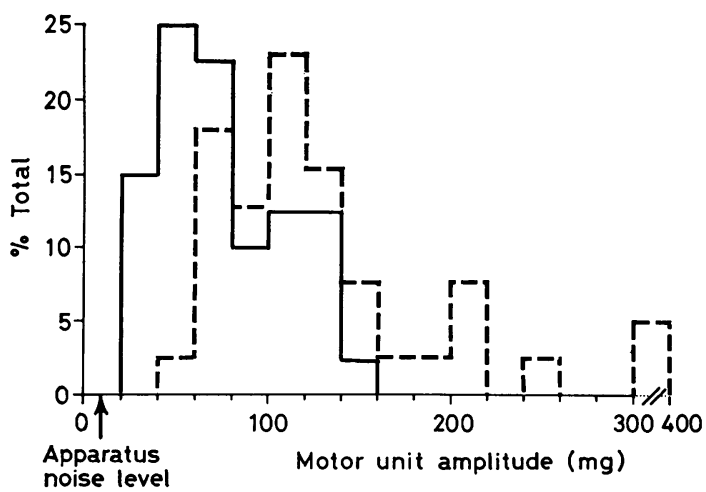

FIG. 4. Distribution of motor unit twitch tensions in normal (broken line) and dystrophic (solid line) muscles. Note that, although many dystrophic units were smaller than normal, the majority were within the normal range.

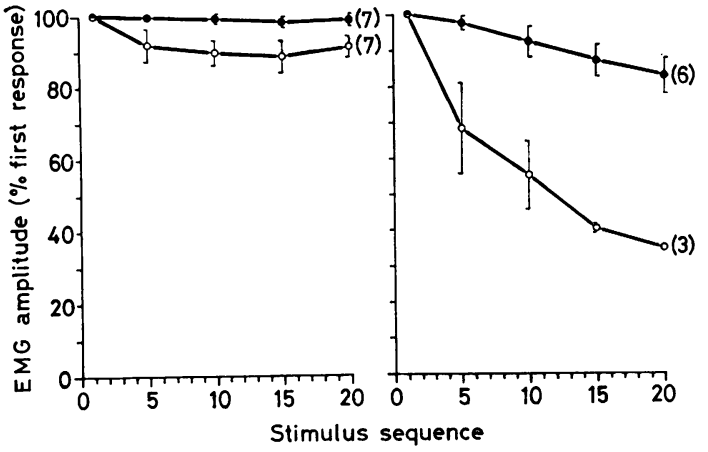

FIG. 5. Relationship between EMG amplitude and stimulus sequence in normal $\bigcirc$ and dystrophic $\bigcirc$ muscles. Left hand panel, stimulus rate 50 shocks/sec, for 400 msec. Right hand panel, stimulus rate 200 shocks/sec for 100 msec. Figures in parentheses represent number of observations. The responses are expressed in terms of the first response in the train and plotted as mean $\pm S E$.

motor units. Several assumptions have to be made in $\stackrel{\omega}{\oplus}$ order to justify this method of estimation.

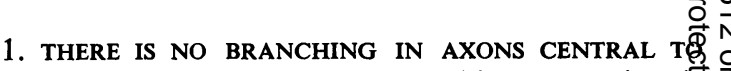
THE STIMULATING ELECTRODES This assumption important, since any branching in the central roots (or in the central stump of the divided sciatic nerved could mean that the very small low thresholg 0 'units' are not whole units. We cannot be certain that such branching did not occur. However, the $\overrightarrow{0}$ electrodes were placed on the nerve trunk approximately $1 \mathrm{~cm}$ from the muscle. Moreover, it has been reported that branching of nerve fibres in the sciatic nerve of rats and monkeys is a 'rare' event (Kashef, quoted by Gilliatt, 1966), and there is no reason to suppose that it should be any less rare in the mouse.

2. THERE IS NO 'CONTAMINATION' OF THE TWITCH RESPONSE BY OTHER MUSCLES ONLY PARTIALLY DENERVATED Although all hind limb muscles other than tibialis anterior were routinely denervated, it was occasionally difficult to completely denervate extensor digitorum longus (EDL) and extensor hallucis longus (EHL). Although these muscles were not attached to the strain gauge, it was felt possible that any tension generated by these muscles $ᄋ$ could be transmitted, attenuated, and recorded as $₹$ small twitches from tibialis anterior. Control 윽 experiments were therefore performed in which a preparation was made and set up as described, but in which EDL and EHL were left normally inner- N vated. The muscle twitch tension and the tension of the first unit was measured, and then, without dis- $N$ mantling the preparation, EDL and EHL were 
completely extirpated. After resting the preparation for $10 \mathrm{~min}$ the experiment was repeated. A typical result is illustrated in Fig. 6. It is apparent that the presence of mechanically active EDL and EHL muscles has no appreciable effect on the recorded responses of the tibialis anterior muscle.

3. THE RESPONSES OF INDIVIDUAL MOTOR UNITS SUMMATE EXACTLY The tibialis anterior is a muscle in which all muscle fibres are arranged more or less parallel. Consequently the motor units act in parallel, and thus their tensions should summate exactly.

4. THE LOW THRESHOLD UNITS RECORDED ARE REPRESENTATIVE OF THE ENTIRE POPULATION OF MOTOR UNITS It is known that the conduction velocities of myelinated nerve fibres are proportional to the fibre diameters (Hursh, 1939) and that large diameter nerve fibres are more excitable than small fibres (Erlanger and Gasser, 1937). In cat muscles, the fastest conducting nerve fibres supply the units capable of exerting the largest tension (McPhedran, Wuerker, and Henneman, 1965; Wuerker, McPhedran, and Henneman, 1965; Burke, 1967). It is possible therefore that our estimate of the number of motor units is low due to the selective stimulation of large units. However, the correlation between nerve fibre diameter and twitch tension is not as precise in 'mixed-muscles' such as gastrocnemius as in slow muscles (Burke, 1967). Moreover, detailed analysis of the data of Close (1967) suggests that no greater error is involved in estimating the

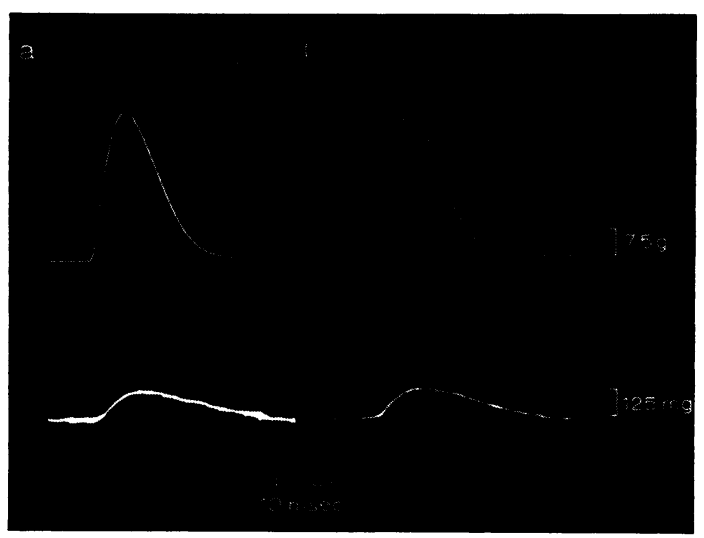

FIG. 6. Maximal muscle twitch response and first motor unit response in a normal tibialis anterior muscle before a, and after $\mathrm{b}$, the removal of $E H B$ and $E D L$ muscles. In $\mathrm{a}$, all muscles were left with innervation complete. Photographs retouched. number of motor units by dividing the total muscle twitch tension by the mean tension of the most excitable motor units, than in making the estimate by dividing the total muscle twitch tension by the mean tension of units randomly excited by stimulation of single ventral root filaments.

5. EACH INCREMENT IN TENSION IS DUE TO THE RECRUITMENT OF ANOTHER UNIT If two aXons have stimulus thresholds close to or identical with each other, a repeated stimulus of a given strength may cause either one unit or the other, or both to fire. Thus, if the two units differ in size, the results may suggest the presence of three rather than two units. Close (1967) also commented on this phenomenon. However, in our experiments, in almost all cases, it was possible to recruit the first four to six units by slowly increasing the stimulus strength without the complication of 'alternation'. When larger numbers of units were searched for, alternation was always present. If alternation was observed during attempts to record the first four units, the experiment was terminated and the results rejected.

A further check on the validity of the method used for estimating the number of motor units was made by counting the number of myelinated nerve fibres in the anterior tibial nerve. In most mammals, a branch of this nerve runs to the dorsum of the foot (Barker and Chin, 1960). In the mouse, this branch is discrete and it is possible to count only those nerve twigs directly involved in the innervation of tibialis anterior. Since, in these twigs, all the sensory fibres will arise within the muscle, the muscle nerve may be assumed to contain a large $(60 \%)$ proportion of efferent fibres (Boyd and Davey, 1968). It may also be assumed that up to $60 \%$ of efferent fibres are skeletomotor(Boyd and Davey, 1968). Six normal and four dystrophic muscle nerves were counted, and typical histograms of normal and dystrophic muscle nerves are shown in Fig. 7. On the basis of the assumptions made above, it was estimated that there are $191 \pm 26 \mathrm{SE}$ motor units in normal muscles, with individual results ranging from 133-314. This is in close agreement with our physiological estimate. Similarly, the anatomical estimate of motor units in dystrophic muscles was $72 \pm 14$ (range 44-106) which is also in close agreement with the physiological estimate (Fig. 8).

[It is also worthy of note that the total number of nerve fibres in dystrophic nerves was so severely reduced, that the reduction cannot be reconciled with a loss of skeletomotor fibres alone. Furthermore, the reduction in nerve fibres was not confined to the large diameter fibres. This suggests that there is a considerable loss of nerve fibres supplying sensory structures in the muscle. Further investi- 


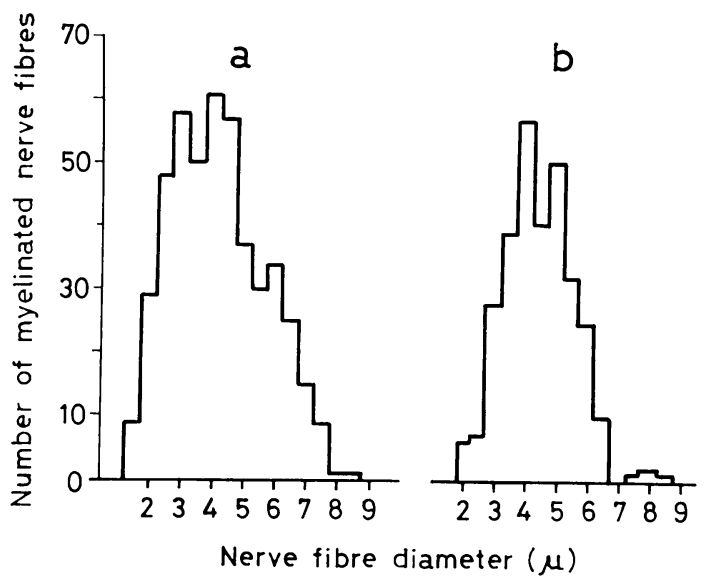

FIG. 7. Distribution of myelinated nerve fibre diameters in the tibialis anterior muscle nerve of, a, a normal animal and, b, a dystrophic animal.

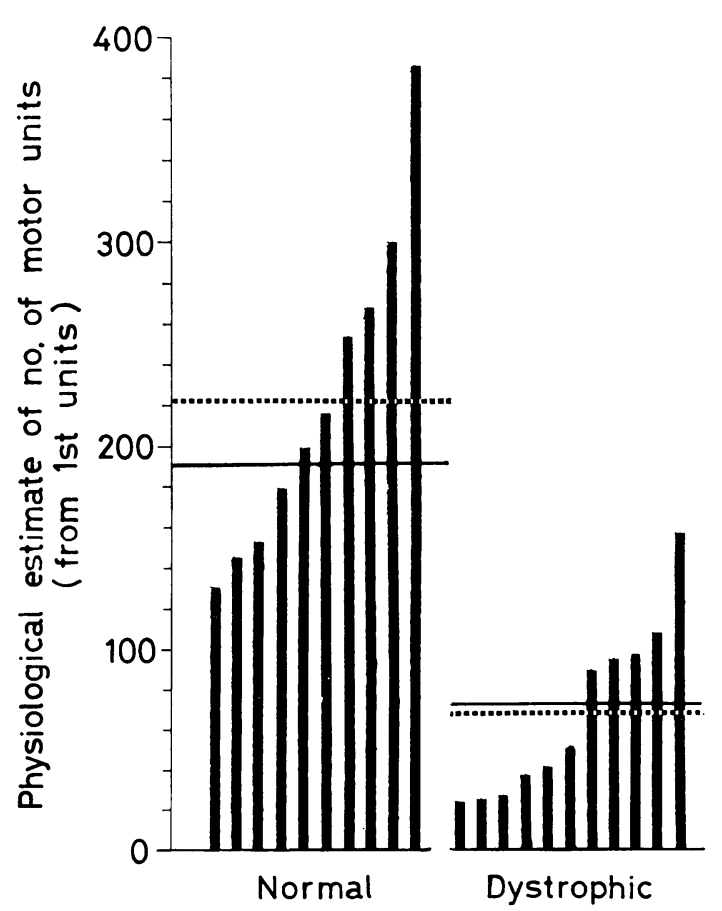

FIG. 8. Physiological estimates of the number of motor units in normal and dystrophic tibialis anterior muscles plotted in rank order. Solid horizontal line represents mean anatomical estimate, broken line represents mean physiological estimate (calculated from maximal twitch tension divided by tension of the most excitable unit). gation of this aspect may provide an explanation for the pathological changes known to occur in dystrophic human spindles (Cazzato and Walton, 1968) and in sensory nerve action potentials (Dreschler, 1963)].

In summary, it would appear that the method of threshold stimulation does give a reasonably reliable estimate of the number of motor units in a muscle. It is also relevant that the estimate of the number of motor units in rat soleus muscle made by Close (1967) using threshold stimulation is in close agreement with the anatomical estimate of motor unit numbers made by Gutmann, Hanzlikova, and Jakoubek (1968).

The finding of a reduced number of motor units in dystrophic mice is of considerable interest since it suggests that 'denervation' is a feature common to both the human and animal dystrophies (Campbell, McComas, and Sica, 1970; McComas and Sica, 1970; McComas, Sica, and Currie, 1970). Dystrophic mice above the age of 2 months are severely crippled, and may exhibit almost total paralysis of $\dot{\omega}$ the hind limbs (Michelson et al., 1955). In view of $\vec{a}$ this paralysis, it is reasonable to consider the possibility that the denervation is due to some form $\vec{N}$ of traumatic injury to the nerves. Fullerton an\& Gilliatt (1967) have described a pressure neuropath 9 in the hind foot of the guinea-pig, and similar 0 injuries are well known in man (Kopell and $\frac{0}{0}$ Thompson, 1963). However, in our experiments, observed evidence of 'denervation' even in animas. of only 4 weeks of age. At this age, dystrophie mice are only very slightly ataxic, and it is unlikely that the 'denervation' is due to traumatic injury.

A second possibility is that the 'denervation' is a secondary phenomenon, and is preceded by a random destruction of muscle fibres as might be expected in a primary myopathy. If this were the case, one might expect an early stage in the disease to be represented by a normal number of weak motor units. As the myopathy progressed, some motor units would become too small to remain viable, and thus, at a late stage one would expect a reduced number of very weak motor units. However, in very young animals (4 weeks old) which may be considered to exhibit 'early dystrophy', although the number of motor units was reduced, the remaining units were quite capable of generating normal twitch tensions. Furthermore, although in the adult mouse there was some reduction in motor unit twitch tension, most units were as efficient as normal units. It would seem, therefore, that the primary cause of murine dystrophy may be in the motor nerves o rather than in the muscle fibres. That many dystrophic motor units are weak is not inconsistent with this conclusion, since it is not unlikely that a 'sick' motor 
unit would become inefficient (and thus weak) before dying completely.

The absence of unusually large motor units in dystrophy muscle suggests that the remaining axons are incapable of reinnervating denervated muscle fibres by the mechanism of collateral sprouting.

If this interpretation of our results is correct, many other observations become more easily understood. This is particularly true of the earlier observation of McComas and Mrożek (1968) that up to $25 \%$ of the fibres of dystrophic tibialis anterior muscles were functionally denervated, a phenomenon originally considered to be secondary to a primary myopathic process.

The dystrophic muscles were both lighter and weaker than normal. The weakness was not simply due to the loss of muscle bulk, since the twitch and tetanic tensions of the muscle were reduced in terms of tension/unit wet weight. This reduction in overall efficiency, also noted by Sandow and Brust (1958), is obviously a reflection of the denervation.

The pathology of murine dystrophy has been extensively reported (West and Murphy, 1960; Pearce and Walton, 1963) and there is general agreement on the main features of dystrophic muscle (fibre atrophy and hypertrophy, central nucleation, proliferation of connective tissue, necrosis, and phagocytosis). It is not surprising that under these conditions the twitch kinetics of the muscles are changed. However, we do not know whether the increase in contraction and halfrelaxation times is due to a change in basic processes in all muscle fibres, or to changes in the visco-elastic properties of the muscles as a whole caused by the presence of large areas of degenerating tissue, or to a certain number of units being relatively spared in the dystrophic process, and thus exerting a relatively greater influence in the muscle. If, for example, slow muscle fibres in tibialis anterior are spared (Brust, 1966; Harris, 1970), then the slowing of the twitch might simply be due to this.

Alternatively, slowing of the twitch, and the reduction in twitch/tetanus ratio could be caused by an increase in series compliance (Hill, 1951). The prolonged half-relaxation time may also be related to the reported deficiency in the calcium accumulating ability of isolated sarcoplasmic reticulum fragments of dystrophic muscle (Sreter, Ikemoto, and Gergely, 1967). It is probable that the changes in the twitch kinetics are caused by several factors.

The maximum rate of rise of tension during the twitch response was reduced in dystrophic muscle, probably as a result of the prolonged contraction time. On the more interesting features such as the optimal rate of stimulation for the maximum rate of rise of tension in dystrophic muscle we have little information. In particular, our difficulty in obtaining such information centred upon the necessity of obtaining consistent responses to repetitive stimulation. We were initially surprised by the apparent lack of viability of the muscles, especially in view of the reports of Brust (1966) and Hinterbüchner et al. (1966) that directly stimulated, curarised dystrophic muscles in vitro were more resistant to 'fatigue' than normal muscles. In many of our experiments, dystrophic muscles were capable of responding to single stimuli, but incapable of responding to high frequency stimulation. This inability to respond mechanically to tetanic stimulation appears to be a consequence of the 'myasthenic-like' response of dystrophic muscles which was observed at stimulus rates of 200 shocks/sec. (Fig. 5). The paradoxical findings of Brust and Hinterbüchner are probably a consequence of the experimental conditions used by them.

It is difficult to be certain that the 'myastheniclike' response is presynaptic rather than postsynaptic in origin. However, reductions in both discharge frequency (Conrad and Glaser, 1964) and amplitude (McComas and Mossawy, 1965) of miniature end plate potentials have been reported in dystrophic muscle, and McComas and Mrożek (1967) showed that many dystrophic muscle fibres were capable of responding to direct stimulation, but not to indirect stimulation. These findings suggest strongly that the 'myasthenic-like' response is presynaptic in origin, although it is not possible to comment on the precise nature of the defect.

Our suggestion that murine dystrophy is essentially a primary neuropathy is the most simple explanation compatible with the known characteristics of the disease. It is important, however, to acknowledge the difference between the term 'denervation' used in the context of this work and when used in the classical sense to describe the total severance of the nervous supply to a muscle. In the latter case the muscle is deprived of transmitter substances and trophic factors (Guth, 1968; Gutmann, 1969) completely and suddenly; in the former, the process is gradual, and the 'denervation' may be preceded by a deficiency in either quantity or quality or 'trophic substance'. If this is the case, then it is not surprising that collateral reinnervation does not occur, and that regeneration in dystrophic muscles is largely abortive (Ross and Hudgson, 1969).

We gratefully acknowledge the advice and criticism of Dr. A. J. McComas, the technical assistance of Trevor Blogg, Colin Wallace and John Wing, and the secretarial assistance of Miss Evelyn Treece-Birch. 
The work was supported by grants from the Medical Research Council, the Muscular Dystrophy Group of Great Britain and the Muscular Dystrophy Associations of America, Inc.

\section{REFERENCES}

Barker, D., and Chin, N. K. (1960). The number and distribution of muscle-spindles in certain muscles of the cat. J. Anat. (Lond.), 94, 473-486.

Boyd, I. A., and Davey, M. R. (1968). Composition of Peripheral Nerves. Livingstone: Edinburgh.

Brown, M. C., and Matthews, P. B. C. (1960). The effect on a muscle twitch of the back response of its motor nerve fibres. J. Physiol. (Lond.), 150, 332-346.

Brust, M. (1965). Contraction enhancement in skeletal muscles of normal and dystrophic mice. Amer. J. Physiol., 208, 425-430.

Brust, M. (1966). Relative resistance to dystrophy of slow skeletal muscle of the mouse. Amer. J. Physiol., 210, 445-451.

Buller, A. J., and Lewis, D. M. (1965). The rate of tension development in isometric tetanic contractions of mammalian fast and slow skeletal muscle. J. Physiol(Lond.), 176, 337-354.

Buller, A. J., Ranatunga, K. W., and Smith, J. M. (1968). The influence of temperature on the contractile characteristics of mammalian fast and slow twitch skeletal muscles. J. Physiol. (Lond.), 196, 82 P.

Burke, R. E. (1967). Motor unit types of cat triceps surae muscle. J. Physiol. (Lond.), 193, 141-160.

Campbell, M. J., McComas, A. J., and Sica, R. E. P. (1970). An electrophysiological study of dystrophia myotonica. J. Physiol. (Lond.), 209, 28-29 P.

Cazzato, G., and Walton, J. N. (1968). The pathology of the muscle spindle: a study of biopsy material in various muscular and neuromuscular diseases. J. neurol. Sci., 7, 15-70.

Close, R. (1967). Properties of motor units in fast and slow skeletal muscles of the rat. J. Physiol. (Lond.), 193, 45-55.

Close, R., and Hoh, J. F. Y. (1968). Influence of temperature on isometric contractions of rat skeletal muscles. Nature (Lond.), 217, 1179-1180.

Conrad, J. T., and Glaser, G. H. (1964). Spontaneous activity at myoneural junction in dystrophic muscle. Arch. Neurol. (Chic.)., 11, 310-316.

Creese, R. (1960). Potassium in different layers of isolated diaphragm. J. Physiol. (Lond.), 154, 133-144.

Creese, R., and Northover, J. (1961). Maintenance of isolated diaphragm with normal sodium content. $J$. Physiol. (Lond.), 155, 343-357.

Dreschler, B. (1963). The sensory nerve action potentials in man with partially de-efferentated muscles (Amyotrophic lateral sclerosis) and with progressive muscular dystrophy. Pp. 449-453. In The Effect of Use and Disuse on Neuromuscular Functions. Edited by E. Gutmann and P. Hnik. Publishing House of the Czechoslovak Academy of Sciences: Prague.

Erlanger, J., and Gasser, H. S. (1937). Electrical Signs of Nervous Activity. University of Pennsylvania Press: Philadelphia. (2nd edition: Oxford University Press: London, 1970.)

Feinstein, B., Lindegard, B., Hyman, E., and Wohlfart, G. (1955). Morphologic studies of motor units in normal human muscles. Acta anat., 23, 127-142.

Fullerton, P. M., and Gilliatt, R. W. (1967). Pressure neuropathy in the hind foot of the guinea pig. J. Neurol. Neurosurg. Psychiat., 30, 18-25.
Gilliatt, R. W. (1966). Axon branching in motor nerves. In Control and Innervation of Skeletal Muscle. Pp. 53-60. Edited by B. L. Andrew. Livingstone: Edinburgh.

Goldspink, G., and Rowe, R. W. D. (1968). The growth and? development of muscle fibres in normal and dystrophico mice. In Research in Muscular Dystrophy; Proc. IVth Symp., pp. 116-128. Pitman Medical: London.

Guth, L. (1968). Trophic influences of nerve on muscle. Physiol. Rev., 48, 645-687.

Gutmann, E. (1969). The trophic function of the nerve cell. Scientia, 104, 122-141.

Gutmann, E., Hanzlikova, V., and Jakoubek, B. (1968). Changes in the neuromuscular system in old age. Exp. Geront, 3, 141-146.

Harris, J. B. (1971). The resting membrane potential of fibres of fast and slow twitch muscles in normal and $\overline{\bar{D}}$ dystrophic mice. J. neurol. Sci., 12, 45-52.

Hill, A. V. (1951). The effect of series compliance on the tension developed in a muscle twitch. Proc. roy. Soc. B., N 138, 325-329.

Hinterbüchner, L. P., Angyan, A., and Hirsch, M. (1966). $\overrightarrow{0}$ Effects of series of tetani on dystrophic and normal muscles of mouse. Amer. J. Physiol., 211, 915-918.

Hursh, J. B. (1939). Conduction velocity and diameter of nerve fibres. Amer. J. Physiol., 127, 131-139.

Kopell, H. P., and Thompson, W. A. L. (1963). Peripheral? Entrapment Neuropathies. William and Wilkins: Baltimore.

Krnjević, K., and Miledi, R. (1958). Failure of neuromuscular + propagation in rats. J. Physiol. (Lond.), 140, 440-461. ir

McComas, A. J., and Mossawy, S. J. (1965) Electro or physiological investigation of normal and dystropher $\vec{N}$ muscles in mice In Research in Muscular Dystroph, 0 Proceedings of IIIrd Symposium, pp. 317-341. Pitm范 Medical: London.

McComas, A. J., and Mrozek, K. (1967). Denervato muscle fibres in hereditary mouse dystrophy. J. Neurg. $\frac{9}{0}$ Neurosurg. Psychiat., 30, 526-530.

McComas, A. J., and Sica, R. E. P. (1970). Muscula dystrophy-myopathy or neuropathy? Lancet, 1, 1119.్․

McComas, A. J., Sica, R. E. P., and Currie, S. (1970) Muscular dystrophy: evidence for a neural factor. Nature. (Lond.), 226, 1263-1264.

McPhedran, A. M., Wuerker, R. B., and Henneman, E. (1965). Properties of motor units in a homogeneous red muscle (soleus) of the cat. J. Neurophysiol., 28, 71-84.

Michelson, A. M., Russell, E. S., and Harman, P. J. (1955). ฏ Dystrophia muscularis: a hereditary primary myopathy in $\frac{}{\mathbb{D}}$ the house mouse. Proc. nat. Acad. Sci. (Wash.), 41, 1079. @ 1084.

Pearce, G. W., and Walton, J. N. (1963). A histological study of muscle from the Bar Harbor strain of dystrophic mice. J. Path. Bact., 86, 25-33.

Ross, K. F. A., and Hudgson, P. (1969). Tissue culture in muscle disease. In Disorders of Voluntary Muscle, pp. 319361. Edited by J. N. Walton. Churchill: London.

Sandow, A., and Brust, M. (1958). Contractility of dystrophic mouse muscle. Amer. J. Physiol., 194, 557-563.

Sreter, F. A., Ikemoto, N., and Gergely, J. (1967). Studies on the fragmented sarcoplasmic reticulum of normal and $\delta$ dystrophic mouse muscle. In Exploratory Concepts in Muscular Dystrophy and Related Disorders, pp. 289-298. Edited by A. T. Milhorat. Excerpta Medica Foundation: Amsterdam.

West, W. T., and Murphy, E. D. (1960). Histopathology of $\frac{D}{2}$ hereditary, progressive muscular dystrophy in inbred strain 129 mice. Anat. Rec., 137, 279-295.

Wuerker, R. B., McPhedran, A. M., and Henneman, E. (1965). Properties of motor units in a heterogeneous pale $N$ muscle (M. gastrocnemius) of the cat. J. Neurophysiol., 28, 85-99. 